\title{
GLOBAL CRISIS AND UPGRADING OF MNCS' \\ MANUFACTURING SUBSIDIARIES: A CASE STUDY \\ OF HUNGARY
}

\section{Szalavetz, A.}

The purpose of this paper is to investigate the impact of MNCs' crisis-driven cost-cutting and organizational restructuring actions on their local subsidiaries in Hungary. We hypothesize that much of the cost-cutting minded and efficiency-focused organizational transformation prompted by the global crisis of 2008 can actually be beneficial to some subsidiaries. Drawing on interviews carried out at 13 manufacturing subsidiaries, we find that upgrading occurs partly as a consequence of MNCs' pressure to reduce costs and improve efficiency, partly as an outcome of organizational restructuring and resources reallocation, and partly as a result of an increasing delegation of advanced functions to production subsidiaries. Although the Hungarian subsidiaries were on the receiving end: they hosted some of the relocated production activities, the main managerial implication is that caution is needed, success often breeds failure. The resulting overconfidence may prevent local managers and policy-makers from monitoring and analyzing industry-specific technological and market trends to detect opportunities and threats as early as possible.

Keywords: crisis adaptation; manufacturing subsidiaries; upgrading; Hungary

JEL classification: D22, D23, D81, F23

\section{Introduction}

While there is a rapidly growing body of research on multinational corporations' (MNCs) strategic responses to the global financial crisis of 2008-2011, relatively little is known about the impact of the cost-cutting and restructuring actions on MNCs' production subsidiaries (Chung et al., 2010). The fate of production subsidiaries at times of adverse turns in the business cycle is particularly interesting for actors in relatively underdeveloped economies, since the reconfiguration of MNCs' resources may represent important upgrading opportunities for them, or, conversely, they might involve downgrading and even closure. In Central and Eastern European (CEE) economies, for example, where the local subsidiaries of efficiency-seeking investors from advanced economies account for the lion's share of manufacturing production, value added and exports (Jindra et al., 2009; Soós, 2015; see also: Pavlínek (2015) for the automotive industry, and Sass (2015) for electronics), the economies are particularly vulnerable to investors' massive withdrawal decisions.

This paper investigates the impact of MNCs' reallocation of resources and value chain optimization moves triggered by the global financial crisis of $2008-2011$ on their CEE subsidiaries that specialize in manufacturing activities. Do these strategic steps result in the downgrading of these subsidiaries, or, conversely, do they open up additional upgrading opportunities for them?

The context of our investigations is Hungary, a small, open economy, whose modernization and industrial upgrading has been driven mostly by the inflow of efficiency-seeking foreign direct investment (Csáki, 2001; Szanyi, 2001). 
We hypothesize that much of MNCs' cost-cutting minded and efficiency-focused organizational transformation can actually be beneficial to some subsidiaries. Upgrading may occur partly as a consequence of MNCs' pressure to reduce costs and improve efficiency, partly as an outcome of MNCs' organizational restructuring and resources reallocation, and partly as a result of the increasing delegation of advanced functions to production subsidiaries.

In line with a number of actors (Domański et al., 2013; Sturgeon and Kawakami, 2011; van Tuijl, 2014), we show that the crisis-triggered restructuring of multinational corporations opened up substantial upgrading possibilities for CEE actors. This success calls for caution, however. The key managerial implication is that this resilience, i.e. local subsidiaries' apparently successful weathering the crisis, may bear the germs of a failure.

\section{Conceptual framework}

Our research is related to three broad strands in the literature. The first one is the corporate restructuring literature that is concerned with firms' financial, organizational and business portfolio restructuring (e.g. Bowman and Singh, 1993; Johnson, 1996). The second is the dynamic capabilities literature (Eisenhardt and Martin 2000, Teece et al. 1997) since firms' multifaceted responses to the changing external environment are often manifested in the reconfiguration of their structures and the realignment of their resources.

The third strand, the global value chain framework of analysis (OECD, 2013) has influenced almost all segments of the international business literature. Global value chains are flexible and dynamic (constantly evolving) forms of business organization. One manifestation of this evolution is the upgrading of selected actors along the value chain. Upgrading denotes actors' movement towards higher-than-before value adding activities. This can take several forms: it may take place in the field of the products manufactured by the given company (shift to higher-than-before unit-value products), or may be manifested in the efficiency improvement of the production processes (process upgrading), or in the take-up of additional (more knowledge-intensive and higher value generating) business functions by companies specialized previously only in production (functional upgrading). Finally upgrading may be intersectoral, when the accumulated competencies are applied in new sectors that promise larger rents and beneficial externalities (Humphrey and Schmitz, 2002).

A conspicuous current trend in the evolution of global value chains is their geographic consolidation and organizational concentration (Buckley, 2009; Gereffi, 2014). Lead firms rationalize their global supply chains and radically reduce the number of direct suppliers. Supplier firms that can survive this rationalization wave are bigger and more powerful than average, which further augments the competitive pressures that peripheral actors face. Cattaneo et al. (2010) posit that the global crisis has accelerated this structural trend. Nevertheless, crisis has, at the same time, opened up new upgrading opportunities for peripheral actors.

\section{Research Method and Sample}

Since the objective of this paper is to investigate complex, real-world phenomena, multiple case study-based exploratory research was considered the most appropriate method 
of investigation (Eisenhardt 1989). ${ }^{1}$ An interview guide containing predominantly openended questions allowed interviewees to provide rich descriptions of complex, multifaceted processes: to speak about crisis-driven organizational transformation and the impact thereof on the surveyed manufacturing subsidiaries. The interviews, 60 to 90 minutes in length, were conducted between September and November 2015. Interviewed managers were, in eleven cases CEOs of Hungarian subsidiaries, in two cases, divisional leaders were interviewed. To preserve anonymity, neither corporate names nor main products will be specified.

In the process of sample selection we applied a purposeful sampling method (Patton, 1990). Our aim was to select information-rich cases: companies whose insights draw on a multiplicity of experiences, i.e. companies whose cases promise observations about issues of central importance to our research. For this sake, we selected large companies, local manufacturing subsidiaries of MNCs that are important global actors of their industries. These companies had been operating in Hungary for at least a decade at the time of the interview.

Altogether, our sample consists of thirteen manufacturing subsidiaries of American, Danish, German, and Swedish MNCs operating in the automotive (2), automotive electronics (3), electronics (4), and machinery (4) industries. On average, these companies had been operating in Hungary for more than 20 years at the time of the interview.

The average number of employees of the surveyed Hungarian subsidiaries was 1,920, in 2014. The average turnover was EUR 608.6 million. These companies are highly export- oriented: the average share of exports to total sales amounts to $82.8 \%$. The surveyed firms account for $21 \%$ of the given industries' total turnover and $9.3 \%$ of these industries' total employment.

When selecting the sample, we immediately faced the problem of respondent bias. In line with global developments with respect to the average tenure and turnover of executives (average tenure shows a continuous decline and CEO turnover increasesSchloetzer et al., 2015), also in Hungary, it was difficult to find large local subsidiaries with interviewed managers in the same managerial position already during the crisis years. In our sample, only six managers out of 13 would fulfil this requirement. Neither were all interviewed managers in the same firm seven or eight years prior the interview: only 11 out of 13. Interestingly, the two 'newcomer CEOs' worked previously (during the crisis years) at another firm in our sample. Nevertheless, all interviewed managers confirmed, they had sufficient information about firm-specific developments during and after the crisis years, and, indeed, the quality of the respondents compensated for the occasional lack of their personal experience in the given position.

1 Using case studies for theory-building is a frequently applied methodological approach in the context of CEE enterprises, since it contributes to gaining in-depth understanding of local contexts and local specifics. This approach allows for contrasting real-world phenomena in CEE with the theoretical tenets of international business literature, developed in the context of advanced economies. A close-to-our-research example is Rugraff and Sass (2016) who investigated the factors that determine MNCs' reaction to the crisis. Drawing on field interviews with Hungarian automotive suppliers, these authors found that the relocation of production to even lower-cost locations was not characteristic in the context of foreign-owned facilities operating in Hungary: a number of 'keep factors' locked automotive investors in their Hungarian location. Another example is Winter (2010) who relied on qualitative interviews with automotive MNCs' Polish subsidiaries to develop a conceptual framework on upgrading, viewed in terms of local subsidiaries' competence acquisition in various business process phases. 
The first couple of questions were intended to set the context and collect information about the multiplicity of crisis-driven organizational transformation processes that affected the organization of the surveyed firms' value chains. The core part of our questions investigated the impact of these changes on the subsidiary's mandates and responsibilities.

\section{Findings}

The managers interviewed maintained that the Hungarian subsidiaries were net beneficiaries of their MNCs' organizational reconfiguration actions. Crisis-driven organizational realignment reinforced the ongoing organic upgrading processes the surveyed subsidiaries already had been experiencing for five to ten years before the crisis.

In some cases, crisis prompted decisions to relocate additional production activities from high-cost subsidiaries to the relatively lower-cost Hungarian location. Moreover, since the surveyed MNCs' reaction to crisis was manifest not only in relocation and retrenchment but also in counter-cyclical investments and targeted acquisitions that were aimed at strengthening their market position, these latter moves have in some cases also proved beneficial for their Hungarian subsidiaries. Production activities that used to be carried out by the newly acquired companies in advanced economies were relocated to the Hungarian premises, together with the related development and testing activities.

Crisis years' and post-crisis relocation moves contributed not only to the capacity expansion of the surveyed Hungarian subsidiaries, but also to the upgrading of their products and processes.

Product upgrading was driven by new products relocated from high-cost locations. In contrast, process upgrading was the outcome of group-wide cost-cutting actions.

'Crisis has brought out existing organizational and production inefficiencies. You know, when we are riding the expansion wave, we pay less attention to the hidden assets - to the huge savings we can achieve with some creative reorganization steps. Furthermore, we have systematically reviewed our processes and identified various opportunities for saving costs'.

Co-location decisions (of development and testing activities) have enhanced the surveyed subsidiaries' functional upgrading. The synergy effects of locating production-related support tasks to the production sites were recognized well before the crisis; nevertheless, these moves became more frequent after the crisis years. Upgrading took new, qualitative turns especially after the location of some shared services centers (SSCs) to the surveyed Hungarian firms. Examples include SSCs in finance, information technology, accounting and procurement.

In some cases, production relocated from production sites in advanced economies ended up in selected neighboring low-cost countries, not in Hungary. Moreover, some activities were even relocated from Hungary to newly established facilities in Romania, Serbia, Ukraine, etc. Interestingly, these moves have opened up upgrading opportunities also for the Hungarian subsidiaries. Production relocation to neighboring low-cost countries required best practice transfer. Patronage activities, such as technical and management consultancy were carried out by the Hungarian experts at the premises of the relatively younger partner subsidiaries in the region.

The managers interviewed emphasized that the delegation of further responsibilities to the Hungarian subsidiaries and the additional upgrading opportunities these actions opened up for them cannot be ascribed only to the impact of the crisis: demonstrated local capabilities have been crucial drivers of their upgrading. 
'Yes, we benefitted from the crisis, but only good goalkeepers have hits in the woodwork' ${ }^{2}$.

'One thing is important to emphasize: although some of the milestones in our evolution date back to the crisis years or happened thereafter, they can only partly be attributed to the crisis. They rather reflect the recognition of our performance and capabilities'.

The incorporation of remanufacturing in group-level business models has also contributed to the functional upgrading of several companies in the sample. Since the value proposition of business models that incorporate remanufacturing is advantageous not only from an environmental perspective but also from the point of view of cost-effectiveness (remanufactured products are lower-cost alternatives to traditional new products-Opresnik and Taisch, 2015)), remanufacturing activities are often located to low-cost production facilities. According to our informants, the sample companies that host remanufacturing activities benefitted from the higher-than-average knowledge-intensity of remanufacturing. Remanufacturing is at the intersection of production and services activities, and it often requires more sophisticated operational competencies than does manufacturing (Opresnik and Taisch, 2015). Accordingly, subsidiaries entrusted with remanufacturing activities (above and beyond their core production tasks) could hire additional engineers and increase the unit value added of their operations.

Some of MNCs' strategic organizational realignment moves have also added to local subsidiaries' perceived degree of upgrading. In the past, functional coordination was typically deployed in the form of hub-and-spoke systems: the satellites received headquarters' (HQ) instructions and implemented them. One outcome of the comprehensive reconfiguration of the surveyed companies' organizations was the transformation of these unidirectional systems - within functions as diverse as R\&D, procurement, human resources management, distribution, and sales. Instead of the hub-and-spoke system, networks with multiple nodes and centers have been created and virtual international teams have been set up. Henceforth, bottom-up charter definition and initiative-taking complemented top-down instruction execution. Increased attention was paid to best practice sharing and exploration of internal collaboration possibilities.

Consequently, subsidiaries became increasingly networked within the MNCs and had numerous horizontal experiences as opposed to the usual vertical and hierarchical dependence on the regional/global HQ.

One caveat, originating in the focus of our research on organizational reconfiguration-driven impacts of the crisis, deserves to be mentioned here. The hitherto detailed beneficial impacts of the crisis on the surveyed subsidiaries are not intended to suggest that these companies did not face declines in sales and employment. Most of them were forced to implement similar retrenchment programs as their mother companies: job cuts (however, this affected mainly temporary agency workers), pay cuts, reduced bonuses, short-time work programs, curtailed investment plans, and so forth. Nevertheless, turbulent times were quickly over at practically every company in the sample, partly because of the above-detailed relocations.

2 'Only good goalkeepers have hits in the woodwork' is a Hungarian proverb. Its meaning in this context is that the firm's gaining from crisis-driven intra-MNC reallocation moves cannot be interpreted purely as a lucky development: they have 'deserved' their mother company's increased resource commitment because of their excellent performance. 


\section{Conclusions}

This paper has argued that the surveyed Hungarian subsidiaries have benefitted from their owners' cost-cutting and restructuring actions. They were on the receiving end; they hosted some of the relocated production activities. Moreover, the recognized necessity of task integration and of co-location-driven synergy effects has intensified the ongoing functional upgrading processes at the surveyed subsidiaries. Consequently, in the wake of MNCs' strategic redesign of their organizational architecture, their overall position has improved.

Note that a major limitation of this study is the dominance of success stories. This suggests an unfounded and certainly misleading postulation that Hungarian subsidiaries are well-established to withstand adverse turns in the business cycle: they can stably and enduringly rely on their existing locational advantages.

As the development of an outlier firm in the sample demonstrates, this is not necessarily the case. Following a period of gradual upgrading in which R\&D and IT development activities were located to the expanding Hungarian production facilities, the owner decided to consolidate $R \& D$ activities in the Romanian subsidiary. The global crisis has further reinforced the functional upgrading of the Romanian location. New R\&D centers were established, and highly skilled employment increased rapidly in the Romanian facility. R\&D activities in the Hungarian location have been phased out. Meanwhile, the Romanian facilities were chosen as the location of newly established SSCs (in IT and in procurement). The product mix at the manufacturing facility in Budapest changed. The new product mix consists of less-sophisticated products than before, albeit with much longer production runs.

On one hand, this contributed to significantly increased turnover and employment, on the other hand, this transformation represents downgrading from the point of view of the knowledge-intensity and the unit value added ratio of production.

Although this case is exceptional in our sample, it still suggests that crisis-driven additional product and/or functional upgrading are not automatic developments for manufacturing subsidiaries in low-cost locations.

Consequently, the main managerial implication of this finding is related to the title of a famous Harvard Business Review article: 'Why leaders don't learn from success' (Gino and Pisano, 2011). According to Gino and Pisano (2011), success hinders learning both at the individual and organizational level. Some of the above quotes demonstrate that Hungarian managers could not avoid the trap of a 'fundamental attribution error' (when we succeed we are likely to conclude that our talent and our strategy are the reasons): they are overconfident, claiming that their demonstrated capabilities explain their successful weathering the crisis. Yet, future developments, for example technological change in general, and the reorganization of global value chains triggered by new industrial technologies in particular, may hit Hungarian (and CEE) manufacturing actors' global value chain position, especially if local managers and policy-makers fail to monitor and analyze industry-specific technological and market trends to detect opportunities and threats as early as possible.

As for the theoretical implications, our empirical findings demonstrate that the analysis of global value chains requires an evolutionary approach, as both the chains themselves and the participating actors' position undergo continuous transformation. Global 
value chains are subject to both fragmentation and consolidation / concentration. HQs' strategic orientation keeps changing as they flexibly react to changing external environment. Subsidiary upgrading is not unidirectional: although past dependence is certainly an important explanatory factor (prior investment commitments breed further investment), past achievements may wane as a result of HQs' decision to downgrade or dispose of selected business units / facilities. At the same time, even the interpretation of individual developments is far from unambiguous: for example, the case of the outlier firm in our sample may be interpreted as upgrading (expansion of output and increase in employment) or as downgrading (shift to less sophisticated products).

This research has a number of additional limitations. A primary limitation is sample selection bias; large, global MNCs may weather the crisis more easily than family-owned internationalized ventures with a couple of low-cost production facilities. Crisis-driven adjustment and reorganization steps, as well as reliance on counter-cyclical strategies, may significantly differ across various size categories.

The strong industry-specific character of the drivers of steps for organizational reconfiguration represents another limitation. Further research is required to explore the factors that influenced the reaction of MNCs to the global crisis in other industries.

Finally, this research has not controlled for home and host country-specific institutional factors that also might have influenced the surveyed MNCs' behavior. Furthermore, the results are confined to Hungary, and it would be important to see if they are confirmed in other CEE economies.

\section{References}

Bowman, E. H., \& Singh, H. (1993). Corporate restructuring: Reconfiguring the firm. Strategic Management Journal, 14(S1), 5-14.

Buckley, P. J. (2009). The impact of the global factory on economic development. Journal of World Business, 44(2), 131-143.

Cattaneo, O., Gereffi, G., \& Staritz, C. (2010). Global Value Chains in a Postcrisis World. A Development Perspective. Washington: The World Bank.

Chung, C. C., Lee, S. H., Beamish, P. W., \& Isobe, T. (2010). Subsidiary expansion/contraction during times of economic crisis. Journal of International Business Studies, 41 (3), 500-516.

Csáki, Gy. (2001). The inflow of foreign direct investment into Hungary. In: Csáki, Gy., \& Karsai, G. (Eds.) From Transition to Integration. Macroeconomic Development in Hungary 1990-2002. New York, Columbia University Press, pp. 226-261.

Domański, B., Guzik, R., Gwosdz, K., \& Dej, M. (2013). The crisis and beyond: the dynamics and restructuring of automotive industry in Poland. International Journal of Automotive Technology and Management, 13(2), 151-166.

Eisenhardt, K.M. (1989). Building theories from case study research. Academy of Management Review, 14(4), 532-550.

Eisenhardt, K. M., \& Martin, J. A. (2000). Dynamic capabilities: what are they? Strategic Management Journal, 21(10/11), 1105-1121.

Gino, F., \& Pisano, G. P. (2011). Why leaders don't learn from success. Harvard Business Review, 89(4), 68-74.

Humphrey, J., \& Schmitz, H. (2002). How does insertion in global value chains affect upgrading in industrial clusters? Regional Studies, 36(9), 1017-1027. 
Jindra, B., Giroud, A., \& Scott-Kennel, J. (2009). Subsidiary roles, vertical linkages and economic development: Lessons from transition economies. Journal of World Business, 44(2), 167-179.

Johnson, R. A. (1996). Antecedents and outcomes of corporate refocusing. Journal of Management, 22(3), 439-483.

OECD (2013). Interconnected economies: Benefiting from global value chains. Paris: OECD

Opresnik, D., \& Taisch, M. (2015). The manufacturer's value chain as a service-the case of remanufacturing. Journal of Remanufacturing, 5(1), 1-23.

Patton, M.Q. (1990). Qualitative evaluation and research methods. Newbury Park, CA: SAGE Publications.

Pavlínek, P. (2015). The impact of the 2008-2009 crisis on the automotive industry: global trends and firm-level effects in Central Europe. European Urban and Regional Studies, 22(1), 20-40.

Rugraff, E., \& Sass, M. (2016). Voting for Staying. Why didn't the Foreign-Owned Automotive Component Suppliers Relocate their Activity from Hungary to Lower-Wage Countries as a Response to the Economic Crisis? Post-Communist Economies, 28(1), 16-33.

Sass, M. (2015). FDI trends and patterns in electronics. In: Galgóczi, B., Drahokoupil, J., \& Bernaciak, M. (Eds.): Foreign investment in eastern and southern Europe after 2008. 257-295.

Schloetzer, J.D., Tonello, M., \& Aguilar, M. (2015). CEO Succession Practices, 2015 Edition. The Conference Board Research Report R-1492-12-RR.

Soós, K. A. (2015). Geographical and sectorial concentration in Czech, Hungarian and Slovak exports. Institute of Economics CERS HAS Discussion Papers, No. 48.

Sturgeon, T. J., \& Kawakami, M. (2011). Global value chains in the electronics industry: characteristics, crisis, and upgrading opportunities for firms from developing countries. International Journal of Technological Learning, Innovation and Development, 4(1-3), 120-147.

Szanyi, M. (2001). Privatization and greenfield FDI in the economic restructuring of Hungary. Transnational Corporations, 10(3), 25-38.

Teece, D. J., Pisano, G., \& Shuen, A. (1997). Dynamic capabilities and strategic management. Strategic Management Journal, 18(7), 509-533.

Van Tuijl, E. (2014). Car makers and upgrading: Renault in Romania. Journal of Business Strategy, 35(2), 13-18.

Winter, J. (2010). Upgrading of TNC subsidiaries: The case of the Polish automotive industry. International Journal of Automotive Technology and Management, 10(2-3), 145-160.

\section{Author}

\section{Andrea Szalavetz}

Senior research fellow

Institute of World Economics, MTA KRTK

45, Budaörsi út, H-1112 Budapest, Hungary

szalavetz.andrea@krtk.mta.hu

This research was supported by the Institute of Economic Research of the Hitotsubashi University Tokyo. The author thanks Tammy Bickett for providing editorial assistance. 